\title{
Comparison of Halogen with Proton Transfer. Symmetric and Asymmetric Systems
}

\author{
Jia Lu and Steve Scheiner* \\ Department of Chemistry \& Biochemistry \\ Utah State University \\ Logan, UT 84322-0300
}

\begin{abstract}
The transfer of the halogen atom $\mathrm{X}$ within $(\mathrm{A} \cdot \mathrm{X} \cdot \mathrm{A})^{+}$systems was calculated for $\mathrm{A}=\mathrm{NH}_{3}, \mathrm{OH}_{2}$, and $\mathrm{CH}_{3}$, and where $\mathrm{X}=\mathrm{Cl}, \mathrm{Br}$, and $\mathrm{I}$. These potentials are similar to those computed for equivalent proton transfers. Each contains a single symmetric well for short $\mathrm{R}(\mathrm{A} \cdot \mathrm{A})$ distances. As $\mathrm{R}$ is stretched a second minimum appears, separated from the first by a transfer barrier $\mathrm{E}^{\dagger}$ which climbs quickly as $\mathrm{R}$ is elongated. The central X prefers association with the $\mathrm{N}$ in asymmetric systems $\left(\mathrm{H}_{3} \mathrm{NX} . \mathrm{OH}_{2}\right)^{+}$, but a second $\left(\mathrm{H}_{3} \mathrm{~N} . . \mathrm{XOH}_{2}\right)^{+}$ minimum, albeit less stable than the first, can appear if $\mathrm{R}(\mathrm{N} . . \mathrm{O})$ is stretched.

*e-mail: steve.scheiner@usu.edu
\end{abstract}

keywords: double-well potential; halogen bond; transfer barrier 


\section{Introduction}

One of the simplest and most prevalent elementary reactions in chemistry involves the transfer of a proton from one molecular entity to another. This process underlies all of acid-base chemistry, and is an integral component of countless catalytic and enzymatic reactions. Its importance has motivated an enormous body of research into its most fundamental aspects [1-3]. The influence of the $\mathrm{pK}$ of the two competing groups on the transfer energetics is well understood, as is the effect of the geometry of the Hbond connecting them [4-9]. The relationship between transfer energetics and kinetics has become clearer, as has the contribution made by quantum mechanical tunneling of the light proton [10-12].

Recent years have witnessed the growing recognition of an analogue to H-bonding, wherein the central proton is replaced by any of several halogen atoms X [13,14]. Although at first sight counterintuitive that a highly electronegative halogen, with its partial negative atomic charge, might act as a bridge to a nucleophile, this paradox is resolved by consideration of the spatial distribution of electron density around this atom. A polar flattening and depletion of the density along the extension of the R-X bond produces a region of positive potential, which is commonly referred to as a $\sigma$-hole, which can in turn attract an electrophile [15-17]. Study of the halogen bond (XB) has yielded a great deal of insight [18-21] into the source of their intrinsic strength, rivaling that of its H-bond cousin, and how it is affected by the identity of the halogen atom, its substituents, and its spectroscopic and geometric signature [22-26].

Just as the bridging proton of a $\mathrm{HB}$ can transfer between the two participating units, one can in principle imagine the same sort of a transfer of a halogen atom within a XB. And indeed, given the many similarities between these two noncovalent bonds, it would be surprising if such a transfer were not possible. There is in fact ample precedent for the idea of a transfer of a halogen ion or atom between species. In 2001, Grinblat et al [27] had reviewed prior findings and pointed out similarities between proton and halogen transfer. They then went on to provide comprehensive kinetic data on the transfer of a $\mathrm{Br}$ atom between a pair of anions. After noting that the $\mathrm{Br}$ transfer is much faster than that of a proton, they questioned the validity of invoking nucleophilicity as a guiding principle in these processes. The transfer of the larger I atom was later documented [28] by crystal and computational data, with some sensitivity observed for the nature of the donor and acceptor groups.

There have been a series of computational studies of halogen bonding [29-34] wherein the halogen atom in question went beyond simply forming such a bond, but seemed to transfer, at least partially, from one molecular entity to the other. One work [29] noted this transfer is facilitated if the $\mathrm{X}$ is shared by atoms more electronegative than $\mathrm{C}$, and that $\mathrm{Br}$ seemed to transfer more quickly than does $\mathrm{Cl}$. When placed between a pair of $\mathrm{N}$ atoms [35], I favored a symmetric position, equally shared between the donor and acceptor. Indeed, NMR and calculations found such a symmetric position was favored for a number of 
systems involving pyridine units [36], in clear contrast to the asymmetric proton position in analogous $\mathrm{H}-$ bonded complexes, which was confirmed for $\mathrm{X}=\mathrm{I}$ as well [37]. Indeed, this symmetric I position seems quite general as varying substituents on the pyridine units [38] does not change the situation. A later work confirmed these findings [39] but also presented evidence that $\mathrm{F}$ behaves in an opposite manner, favoring an asymmetric position. The latter idea has been countered by the finding [40,41] of symmetric fluoronium ions. However, the situation may change when both the donor and acceptor groups lie on the same molecule, as shown [42] by recent NMR and computational data that indicate a preference for an asymmetric X position. Calculations [43] have confirmed the dominance of symmetric single-well XT potentials, at least for the idealized transfer between $\mathrm{NH}_{3}$ subunits, and considered how the distance between donor and acceptor groups might play into the situation.

There are a number of important and fundamental questions that remain unanswered. At what point does a symmetric single-well halogen transfer (XT) potential transition to a double-well potential? What is the energy barrier separating the two X positions, and how is this barrier affected by the length of the XB? Do the properties of the $\mathrm{X}$ transfer depend upon the identity of the $\mathrm{X}$ atom, i.e. $\mathrm{Cl}$ vs $\mathrm{Br}$ vs $\mathrm{I}$, and if so, how? How is a symmetric $X$ transfer between a pair of identical subunits modified in an asymmetric system when these two units differ from one another? How do the various facets of the XT process differ from the better understood proton transfer?

The current work is designed to answer these questions in a detailed and systematic fashion by application of quantum chemical methods. Symmetric $\left(\mathrm{A}-\mathrm{X}^{+}-\mathrm{A}\right)$ systems are first constructed composed of identical A subunits. The R(A..A) distance is held to a series of constant XB lengths so as to monitor when the XT potential transforms from single to double well, and how quickly the barrier rises as this distance is elongated. Asymmetry is introduced into the system by way of different A subunits, in order to determine its influence on the XT properties. All of these properties are compared to the same quantities of the proton transfer process by replacing $\mathrm{X}$ by $\mathrm{H}$.

\section{Methods and Systems}

Both symmetric and asymmetric systems were selected to examine the $\mathrm{H}$ or $\mathrm{X}$ transfer. Symmetric systems consisted of a pair of first-row atom hydride molecules sharing a $\mathrm{H}$ or X cation $\left(\mathrm{H}_{\mathrm{n}} \mathrm{A}-\mathrm{X}-\mathrm{AH}\right)^{+}(\mathrm{A}=$ $\mathrm{C}, \mathrm{N}$, or $\mathrm{O}, \mathrm{n}=2$, or 3 , and $\mathrm{X}=\mathrm{H}, \mathrm{Cl}, \mathrm{Br}$ or I). When fully optimized, most of these systems led to a fully symmetric geometry wherein the $\mathrm{X}$ ion lies midway between the two $\mathrm{A}$ atoms. The intermolecular $\mathrm{R}(\mathrm{A} \cdot . \mathrm{A})$ distance was then stretched to a variety of lengths, and held fixed while the central $\mathrm{X}$ was allowed to move between them, optimizing all parameters other than the chosen $\mathrm{R}$, tracing out a transfer potential. As described below, for stretches of R(A..A) beyond a certain critical length, the transfer potential alters its shape from a central single well, to a double-well potential, with an energy barrier $\mathrm{E}^{\dagger}$ separating these two 
equivalent wells. As an example asymmetric system, with two different molecules competing for the central ion, $\left(\mathrm{H}_{3} \mathrm{~N}-\mathrm{X}-\mathrm{H}_{2} \mathrm{O}\right)^{+}$was chosen. Whether of single or double-well shape, this potential will not be symmetric regardless of the selected $\mathrm{R}(\mathrm{N} \cdot \mathrm{O})$ intermolecular distance.

Quantum calculations made use of the Gaussian-09 program [44] at the second-order Møller-Plesset (MP2) level. The aug-cc-pVDZ basis set was employed for all atoms with the exception of I for which the aug-cc-pVDZ-PP pseudopotential was used so as to incorporate relativistic effects. The reliability of such methods applied in similar systems is supported by previous work [45-49]. Geometries were optimized with certain restrictions applied as detailed below.

\section{Results}

The energy barriers separating the two equivalent minima in the transfer potentials of the $\left(\mathrm{H}_{3} \mathrm{~N}-\mathrm{X}\right.$ $\left.\mathrm{NH}_{3}\right)^{+}$systems are displayed in Fig 1. The intersection of each curve with the abscissa indicates the transition from single to double well potential. So for example, the transfer potential for $\left(\mathrm{H}_{3} \mathrm{~N}-\mathrm{H}-\mathrm{NH}_{3}\right)^{+}$ contains a single symmetric well for $\mathrm{R}(\mathrm{N} \cdot \mathrm{N})<2.5 \AA$, while this transition occurs for the much longer 5.2 $\AA$ for $\left(\mathrm{H}_{3} \mathrm{~N}-\mathrm{I}-\mathrm{NH}_{3}\right)^{+}$. In fact, this transition point corresponds to the size of the central ion: $\mathrm{H}<\mathrm{Cl}<\mathrm{Br}<$ I. In each case, the barrier grows quickly as the $\mathrm{N}$ atoms are further separated. This growth is roughly linear with $\mathrm{R}(\mathrm{N} \cdot \mathrm{N})$, with correlation coefficients (in orange in Fig 1) all exceeding 0.99. The slopes of the curves in Fig 1 are displayed in blue, and are roughly $30 \mathrm{kcal} / \mathrm{mol}-\AA$ A for the halogen ions; the larger slope of $46 \mathrm{kcal} / \mathrm{mol}-\AA$ p portrays a sharper rise for a central proton. These curves are very nearly parallel to one another, with slopes of roughly $30 \mathrm{kcal} / \mathrm{mol}-\AA$ for the halogen transfer systems, but with a somewhat faster growth for $\mathrm{H}$.

Analogous data are presented in Fig 2 for the corresponding interoxygen transfer in $\left(\mathrm{H}_{2} \mathrm{O}-\mathrm{X}-\mathrm{OH}\right)^{+}$. These data fit similar patterns as in Fig 1 in that there is a roughly linear growth of $E^{\dagger}$ with $\mathrm{R}$. There are certain differences as well. In the first place, the transition from single to double well potential occurs at slightly shorter intermolecular distances for the oxygen systems. The barrier rises a bit more slowly for $\left(\mathrm{H}_{2} \mathrm{O}-\mathrm{I}-\mathrm{OH}_{2}\right)^{+}$and $\left(\mathrm{H}_{2} \mathrm{O}-\mathrm{Br}-\mathrm{OH}_{2}\right)^{+}$than for the inter-nitrogen transfers, although there are no significant differences noted for $\mathrm{X}=\mathrm{H}$ or $\mathrm{Cl}$.

This pattern continues for the $\left(\mathrm{H}_{3} \mathrm{C}-\mathrm{H}-\mathrm{CH}_{3}\right)^{+}$system, as illustrated by the resemblance of Fig 3 to Figs 1 and 2. The chief difference lies in the slopes of the curves which are a bit more gradual in the C-systems, for all central ions $\mathrm{X}^{+}$. The transition point where a double-well potential collapses into a single well occurs at a somewhat longer intermolecular distance for the intercarbon system. This transition occurs, for example, at roughly $2.5 \mathrm{~A}$ for $\left(\mathrm{H}_{3} \mathrm{~N}-\mathrm{H}-\mathrm{NH}_{3}\right)^{+}$and $\left(\mathrm{H}_{2} \mathrm{O}-\mathrm{H}-\mathrm{OH}_{2}\right)^{+}$, but at $3.0 \AA$ for the C-analogue.

Whereas the $\mathrm{NH}_{3}$ and $\mathrm{OH}_{2}$ monomers each represent a closed-shell molecule, the two $\mathrm{CH}_{3}$ entities each comprise an open-shell radical. So it would be sensible to consider not only the closed-shell singlet $\left(\mathrm{H}_{3} \mathrm{C}\right.$ - 
$\left.\mathrm{H}-\mathrm{CH}_{3}\right)^{+}$but also a triplet state. In doing so, however, there are substantial changes in geometry. For example, the central proton drifts well off of the $\mathrm{C}$... C axis, allowing the single electron on each $\mathrm{CH}_{3}$ unit to unite into a covalent $\mathrm{C}-\mathrm{C}$ bond. Ignoring this tendency, and forcing the central proton to remain along the intermolecular C--C axis, leads to transfer barriers depicted in Fig 4. One again sees a rapid rise of barrier with stretched $\mathrm{R}(\mathrm{C}-\mathrm{C})$, but with reduced slopes relative to the corresponding singlet state situation. Finally, the proton transfer between a pair of anionic $\mathrm{CH}_{3}{ }^{-}$units would involve no unpaired electrons, so a singlet state would be sufficient. The barrier for this transfer is exhibited in Fig S1 where it rises quite linearly with $\mathrm{R}(\mathrm{C}-\mathrm{C})$. The slope of this increase is nearly identical to that seen in Fig 3 for the corresponding $\left(\mathrm{H}_{3} \mathrm{C}-\mathrm{X}-\mathrm{CH}_{3}\right)^{+}$cation.

One can glean some insight into the distinction between proton and halogen transfer by comparison of Figs 5 and 6, which respectively illustrate the barriers for $\mathrm{H}^{+}$and $\mathrm{Cl}^{+}$transfer. Fig 5 shows that for any given intermolecular distance $\mathrm{R}$, the proton transfer barriers rise steadily in the order: $\mathrm{CHC}<<\mathrm{NHN}<$ $\mathrm{OHO}$, i.e. a clear separation between the three curves. This pattern is altered in the case of $\mathrm{Cl}$ transfers. The $\mathrm{OClO}$ curve remains to the left of $\mathrm{NCIN}$, but the $\mathrm{CClC}$ curve is hardly distinguishable from NCIN. In other words, while the intercarbon proton transfer is much lower than that between a pair of $\mathrm{N}$ atoms, the same cannot be said for the $\mathrm{Cl}^{+}$transfer where there is only a slight difference, and that only at longer distances. Diagrams corresponding to $\mathrm{Br}$ and I transfer are presented in Figs S2 and S3 look much like Fig 6, indicating that Fig 6 is representative of halogen transfers in general.

The systems examined above are all fully symmetric with identical groups serving as donor and acceptor. On the other hand, most systems which participate in $\mathrm{H}$ or halogen bonds will lack this high level of symmetry, so it is important to determine how the asymmetry introduced by the use of different models for the donor and acceptor will influence the transfer potential. This sort of asymmetry was modeled here by placing $\mathrm{NH}_{3}$ and $\mathrm{OH}_{2}$ within the system, and allow them to compete for the bridging proton or halogen within the $\left(\mathrm{H}_{3} \mathrm{~N}-\mathrm{X}-\mathrm{OH}_{2}\right)^{+}$complex. As is evident in Fig 7, the $\mathrm{Cl}^{+}$transfer potential is likewise highly asymmetric, and the most stable position of the $\mathrm{Cl}^{+}$is covalently attached to the $\mathrm{NH}_{3}$ subunit on the left side of the potential. This preference is true for any intermolecular R(N..O) distance. Indeed, it is only for intermolecular distances exceeding $5.2 \AA$ that there is even a second minimum at all, corresponding to the transferred $\left(\mathrm{H}_{3} \mathrm{~N} \cdot \mathrm{ClOH}_{2}\right)^{+}$structure. This secondary minimum is quite a bit higher in energy than $\left(\mathrm{H}_{3} \mathrm{NCl} \cdot \cdot \mathrm{OH}_{2}\right)^{+}$by some $50 \mathrm{kcal} / \mathrm{mol}$. As $\mathrm{R}$ increases beyond $5.3 \AA$, the $\mathrm{Cl}$-transfer barrier begins to rise. For $\mathrm{R}=5.6 \AA$, for example, the barrier that the $\mathrm{Cl}^{+}$would have to surpass in order to transfer back to the $\mathrm{NH}_{3}$ from the $\mathrm{OH}_{2}$ (right to left) is some $12 \mathrm{kcal} / \mathrm{mol}$. The transfer potentials for the other halogen atoms $\mathrm{Br}$ and I in Figs S4 and S5 look very much like those in Fig 7. The only real difference is the R(N*O) at 
which the second minimum occurs in the transfer potentials. As mentioned above, this critical distance is $5.3 \AA$, which increases up to $5.6 \AA$ for $\mathrm{Br}$, and $6.0 \AA$ for $\mathrm{I}$.

The data presented above refer to "rigid" transfers wherein the distance between the non-halogen atoms, viz. O, N, or C, are held fixed as the halogen atom moves between them. Of interest also is the situation when there is no such restriction, as would be the case for the free ions, untethered to any macromolecular skeleton. The distance between the two heavy atoms in the fully optimized ions are presented in Table 1 where it may first be noted that these distances become longer in the order $\mathrm{H}<\mathrm{Cl}<\mathrm{Br}$ $<$ I, i.e. consistent with radius of the central unit. In terms of the dependence upon the identity of the atoms sharing the halogen, this distance increases rather quickly in the cations from $\mathrm{O}$ to $\mathrm{N}$ to $\mathrm{C}$, wherein the $\left(\mathrm{H}_{3} \mathrm{C} \cdot \mathrm{X} \cdot . \mathrm{CH}_{3}\right)^{+}$system is considered in its triplet state. However, this distance is very much shorter if the system is forced into its singlet state. (These distances must be considered in the light of the full geometry. Unlike the other systems considered here, the fully optimized geometry of the singlet $\left(\mathrm{H}_{3} \mathrm{C} \cdot \mathrm{X} \text {.. } \mathrm{CH}_{3}\right)^{+}$ places the X well off of the central C..C axis.) The situation changes when the central cation is sandwiched between a pair of closed-shell $\mathrm{CH}_{3}{ }^{-}$anions. As noted in the penultimate column of Table 1 , the $\mathrm{H}$-bond distance is quite long at $3.558 \AA$, but the halogen bonded complexes are a bit shorter than for the corresponding cationic triplet. Turning to the asymmetric system in the last column, the R(N..O) distances are comparable to the $\mathrm{N} . . \mathrm{N}$ distances in the symmetric cations.

When placed in the context of the energy barriers in the figures, it becomes clear that most of the systems considered here are characterized by a single-well $\mathrm{H} / \mathrm{X}$ transfer potential. That is, a second minimum appears in the potential only when the two units are pulled sufficiently apart from their optimized close intermolecular contact. One exception is the $\mathrm{H}$-bonded $\left(\mathrm{H}_{3} \mathrm{~N} . . \mathrm{H} . . \mathrm{NH}_{3}\right)^{+}$which contains two minima separated by a very small barrier. Systems with a larger barrier separating the two wells are the X-bonded triplet $\left(\mathrm{H}_{3} \mathrm{C} \cdot \mathrm{X} \cdot . \mathrm{CH}_{3}\right)^{+}$cations.

\section{Conclusions}

The transfer of a halogen atom within a X-bonded complex shows strong parallels with proton transfer in the analogous H-bonded systems. In either case, the potential contains a single symmetric well for short $\mathrm{H}$ or X-bond length, which transitions to a double well for longer distance. As the latter continues to grow, the barrier climbs quickly, increasing by approximately $3 \mathrm{kcal} / \mathrm{mol}$ for each $0.1 \AA$ elongation. The point at which this transition from single to double well potential occurs is roughly proportional to the radius of the transferring atom: $\mathrm{H}<<\mathrm{Cl}<\mathrm{Br}<\mathrm{I}$. Transfer between $\mathrm{O}$ atoms requires surmounting a higher barrier than internitrogen transfer at a given XB length, and the transfer between $\mathrm{C}$ atoms is lowest of all. In terms of an asymmetric system, the halogen atom prefers association with $\mathrm{N}$ over $\mathrm{O}$. A second minimum 
corresponding to $\left(\mathrm{H}_{3} \mathrm{~N} \ldots \mathrm{XOH}_{2}\right)^{+}$occurs only for long $\mathrm{R}(\mathrm{N} . . \mathrm{O})$, and this second minimum remains much higher in energy than the preferred $\left(\mathrm{H}_{3} \mathrm{NX} \ldots \mathrm{OH}_{2}\right)^{+}$configuration.

\section{REFERENCES}

[1] E. Caldin, V. Gold, Eds., Proton-Transfer Reactions. Halsted Press, New York, 1975.

[2] J.A. Dodd, S. Baer, C.R. Moylan, J.I. Brauman, J. Am. Chem. Soc. 113 (1991) 5942.

[3] A.J. Kresge, Acc. Chem. Res. 8 (1975) 354.

[4] S. Scheiner, L. Wang, J. Am. Chem. Soc. 115 (1993) 1958.

[5] S. Scheiner, E.A. Hillenbrand, Proc. Nat. Acad. Sci., USA 82 (1985) 2741.

[6] S. Scheiner, Acc. Chem. Res. 18 (1985) 174.

[7] E.A. Hillenbrand, S. Scheiner, J. Am. Chem. Soc. 106 (1984) 6266.

[8] S. Scheiner, X. Duan, Phys. Chem. Chem. Phys. 60 (1991) 874.

[9] S. Scheiner, J. Chem. Phys. 77 (1982) 4039.

[10] A. Kohen, T. Jonsson, J.P. Klinman, Biochem. 36 (1997) 2603.

[11] A.D. Isaacson, L. Wang, S. Scheiner, J. Phys. Chem. 97 (1993) 1765.

[12] S. Scheiner, Z. Latajka, J. Phys. Chem. 91 (1987) 724.

[13] O. Hassel, Science 170 (1970) 497.

[14] F.H. Allen, J.P.M. Lommerse, V.J. Hoy, J.A.K. Howard, G.R. Desiraju, Acta Cryst. B53 (1997) 1006.

[15] S. Ikuta, J. Mol. Struct. (Theochem) 205 (1990) 191.

[16] R. Sedlak, M.H. Kolář, P. Hobza, J. Chem. Theory Comput. 11 (2015) 4727.

[17] T. Clark, M. Hennemann, J.S. Murray, P. Politzer, J. Mol. Model. 13 (2007) 291.

[18] J. Thirman, E. Engelage, S.M. Huber, M. Head-Gordon, Phys. Chem. Chem. Phys. 20 (2018) 905.

[19] M.A.A. Ibrahim, A.A.M. Hasb, Theor. Chem. Acc. 138 (2018) 2.

[20] U. Adhikari, S. Scheiner, J. Phys. Chem. A 116 (2012) 3487.

[21] A. Bauzá, R. Ramis, A. Frontera, J. Phys. Chem. A 118 (2014) 2827.

[22] K.E. Riley, K.-A. Tran, Faraday Disc. 203 (2017) 47.

[23] M.D. Esrafili, P. Mousavian, Chem. Phys. Lett. 678 (2017) 275.

[24] J. Fanfrlík, J. Holub, Z. Růžičková, J. Řezáč, P.D. Lane, D.A. Wann, D. Hnyk, A. Růžička, P. Hobza, ChemPhysChem. 17 (2016) 3373.

[25] W. Zierkiewicz, D.C. Bieńko, D. Michalska, T. Zeegers-Huyskens, J. Comput. Chem. 36 (2015) 821.

[26] I. Alkorta, A. Legon, New J. Chem. 42 (2018) 10548.

[27] J. Grinblat, M. Ben-Zion, S. Hoz, J. Am. Chem. Soc. 123 (2001) 10738.

[28] O. Makhotkina, J. Lieffrig, O. Jeannin, M. Fourmigué, E. Aubert, E. Espinosa, Cryst. Growth Des. 15 (2015) 3464.

[29] J.E. Del Bene, I. Alkorta, J. Elguero, J. Phys. Chem. A 112 (2008) 7925.

[30] J.E. Del Bene, I. Alkorta, J. Elguero, J. Phys. Chem. A 114 (2010) 12958.

[31] J.E. Del Bene, I. Alkorta, J. Elguero, J. Phys. Chem. A 118 (2014) 2360.

[32] I. Alkorta, J. Elguero, J.E. Del Bene, J. Phys. Chem. A 118 (2014) 4222.

[33] I. Alkorta, J. Elguero, J.E. Del Bene, ChemPhysChem. 17 (2016) 3112.

[34] S.M. Chalanchi, I. Alkorta, J. Elguero, D. Quiñonero, ChemPhysChem. 18 (2017) 3462.

[35] A.-C.C. Carlsson, J. Gräfenstein, J.L. Laurila, J. Bergquist, M. Erdélyi, Chem. Commun. 48 (2012) 1458.

[36] A.-C.C. Carlsson, J. Gräfenstein, A. Budnjo, J.L. Laurila, J. Bergquist, A. Karim, R. Kleinmaier, U. Brath, M. Erdélyi, J. Am. Chem. Soc. 134 (2012) 5706. 
[37] D.C. Georgiou, P. Butler, E.C. Browne, D.J.D. Wilson, J.L. Dutton, Austr. J. Chem. 66 (2013) 1179 .

[38] A.-C.C. Carlsson, K. Mehmeti, M. Uhrbom, A. Karim, M. Bedin, R. Puttreddy, R. Kleinmaier, A.A. Neverov, B. Nekoueishahraki, J. Gräfenstein, K. Rissanen, M. Erdélyi, J. Am. Chem. Soc. 138 (2016) 9853.

[39] A. Karim, M. Reitti, A.-C.C. Carlsson, J. Gräfenstein, M. Erdélyi, Chem. Sci. 5 (2014) 3226.

[40] M.D. Struble, M.G. Holl, M.T. Scerba, M.A. Siegler, T. Lectka, J. Am. Chem. Soc. 137 (2015) 11476.

[41] C.R. Pitts, M.G. Holl, T. Lectka, Angew. Chem. Int. Ed. 57 (2018) 1924.

[42] S. Lindblad, K. Mehmeti, A.X. Veiga, B. Nekoueishahraki, J. Gräfenstein, M. Erdélyi, J. Am. Chem. Soc. 140 (2018) 13503.

[43] J. Crugeiras, A. Rios, Phys. Chem. Chem. Phys. 18 (2016) 30961.

[44] M.J. Frisch, G.W. Trucks, H.B. Schlegel, G.E. Scuseria, M.A. Robb, J.R. Cheeseman, G. Scalmani, V. Barone, B. Mennucci, G.A. Petersson, H. Nakatsuji, M. Caricato, X. Li, H.P. Hratchian, A.F. Izmaylov, J. Bloino, G. Zheng, J.L. Sonnenberg, M. Hada, M. Ehara, K. Toyota, R. Fukuda, J. Hasegawa, M. Ishida, T. Nakajima, Y. Honda, O. Kitao, H. Nakai, T. Vreven, J. Montgomery, J. A., J.E. Peralta, F. Ogliaro, M. Bearpark, J.J. Heyd, E. Brothers, K.N. Kudin, V.N. Staroverov, R. Kobayashi, J. Normand, K. Raghavachari, A. Rendell, J.C. Burant, S.S. Iyengar, J. Tomasi, M. Cossi, N. Rega, J.M. Millam, M. Klene, J.E. Knox, J.B. Cross, V. Bakken, C. Adamo, J. Jaramillo, R. Gomperts, R.E. Stratmann, O. Yazyev, A.J. Austin, R. Cammi, C. Pomelli, J.W. Ochterski, R.L. Martin, K. Morokuma, V.G. Zakrzewski, G.A. Voth, P. Salvador, J.J. Dannenberg, S. Dapprich, A.D. Daniels, O. Farkas, J.B. Foresman, J.V. Ortiz, J. Cioslowski, D.J. Fox, Gaussian 09, Wallingford, CT, 2009.

[45] Y. Wang, Y. Zeng, X. Li, L. Meng, X. Zhang, Struct. Chem. 27 (2016) 1427.

[46] L. Spada, Q. Gou, Y. Geboes, W.A. Herrebout, S. Melandri, W. Caminati, J. Phys. Chem. A 120 (2016) 4939.

[47] Q. Tang, Q. Li, Comput. Theor. Chem. 1070 (2015) 21.

[48] W. Li, Y. Zeng, X. Li, Z. Sun, L. Meng, J. Comput. Chem. 36 (2015) 1349.

[49] Y. Geboes, F.D. Proft, W.A. Herrebout, J. Phys. Chem. A 119 (2015) 5597. 
Table 1. X-bond lengths $(\AA)$ in fully optimized geometries

\begin{tabular}{|l|l|l|l|l|l|l|}
\hline & $\mathrm{O} \cdot \cdot \mathrm{X} \cdot \cdot \mathrm{O}+$ & $\mathrm{N} \cdot \cdot \mathrm{X} \cdot \mathrm{N}^{+}$ & $\begin{array}{l}\mathrm{C} \cdot \cdot \mathrm{X} \cdot \mathrm{C}^{+} \\
(\text {triplet) }\end{array}$ & $\begin{array}{l}\mathrm{C} \cdot \cdot \mathrm{X} \cdot \cdot \mathrm{C}^{+} \\
(\text {singlet) }\end{array}$ & $\begin{array}{l}\mathrm{C} \cdot \cdot \mathrm{X} \cdot \mathrm{C}^{-} \\
(\text {singlet) }\end{array}$ & $\mathrm{N} \cdot \cdot \mathrm{X} \cdot \cdot \mathrm{O}^{+}$ \\
\hline $\mathrm{X}=\mathrm{H}$ & 2.399 & $2.717^{\mathrm{a}}$ & 3.063 & 1.944 & $3.558^{\mathrm{a}}$ & 2.707 \\
\hline $\mathrm{X}=\mathrm{Cl}$ & 3.955 & 4.070 & $4.850^{\mathrm{a}}$ & 2.861 & 4.518 & 4.184 \\
\hline $\mathrm{X}=\mathrm{Br}$ & 4.168 & 4.286 & $4.990^{\mathrm{a}}$ & 2.996 & 4.657 & 4.309 \\
\hline $\mathrm{X}=\mathrm{I}$ & 4.510 & 4.631 & $5.238^{\mathrm{a}}$ & 3.216 & 4.857 & 4.613 \\
\hline
\end{tabular}

${ }^{\mathrm{a}}$ double-well potential 


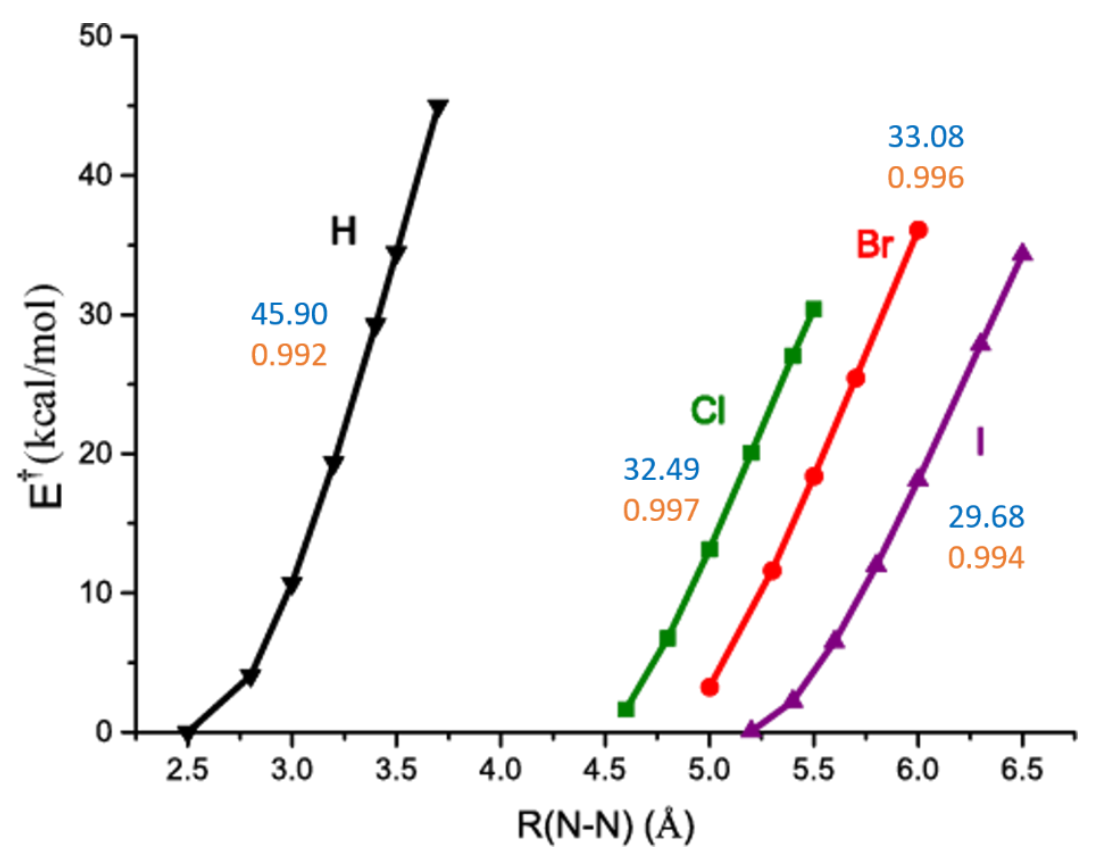

Fig 1. Calculated energy barrier $\mathrm{E}^{\dagger}$ for proton and halogen transfer in symmetric system $\left(\mathrm{H}_{3} \mathrm{~N}-\mathrm{X}-\mathrm{NH}_{3}\right)^{+}$ $(\mathrm{X}=\mathrm{H}, \mathrm{Cl}, \mathrm{Br}$ or I $)$ in terms of intermolecular distance $\mathrm{R}(\mathrm{N}-\mathrm{N})$. Slopes of fit to linear relationship are shown as blue numbers $(\mathrm{kcal} / \mathrm{mol}-\AA$ ) $)$ and the corresponding correlation coefficients are in orange.

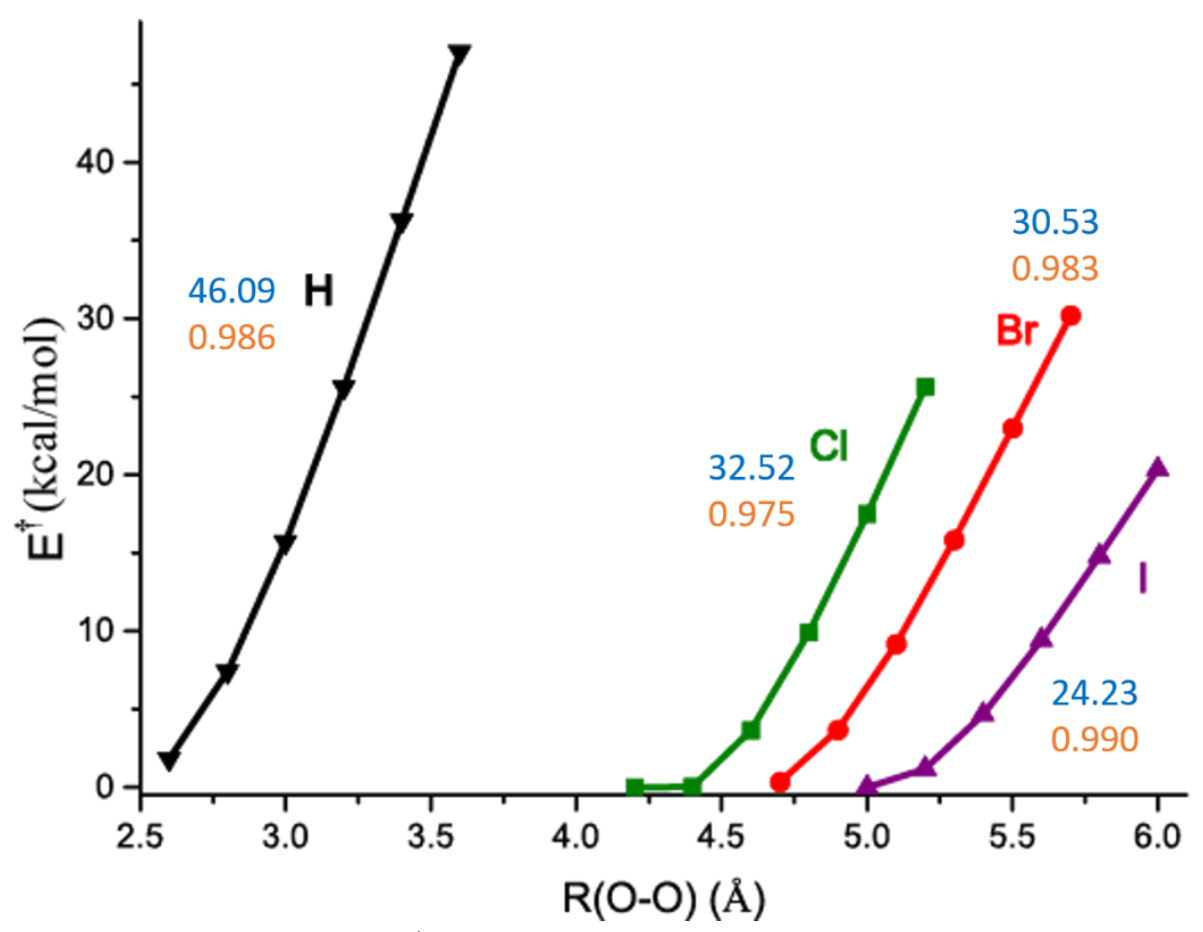

Fig 2. Energy barrier $\mathrm{E}^{\dagger}$ for proton and halogen transfer in symmetric system $\left(\mathrm{H}_{2} \mathrm{O}-\mathrm{X}-\mathrm{OH}_{2}\right)^{+}(\mathrm{X}=\mathrm{H}, \mathrm{Cl}$, $\mathrm{Br}$ or I). Slopes of fit to linear relationship are shown as blue numbers (kcal/mol- $\AA$ ) and the corresponding correlation coefficients are in orange. 


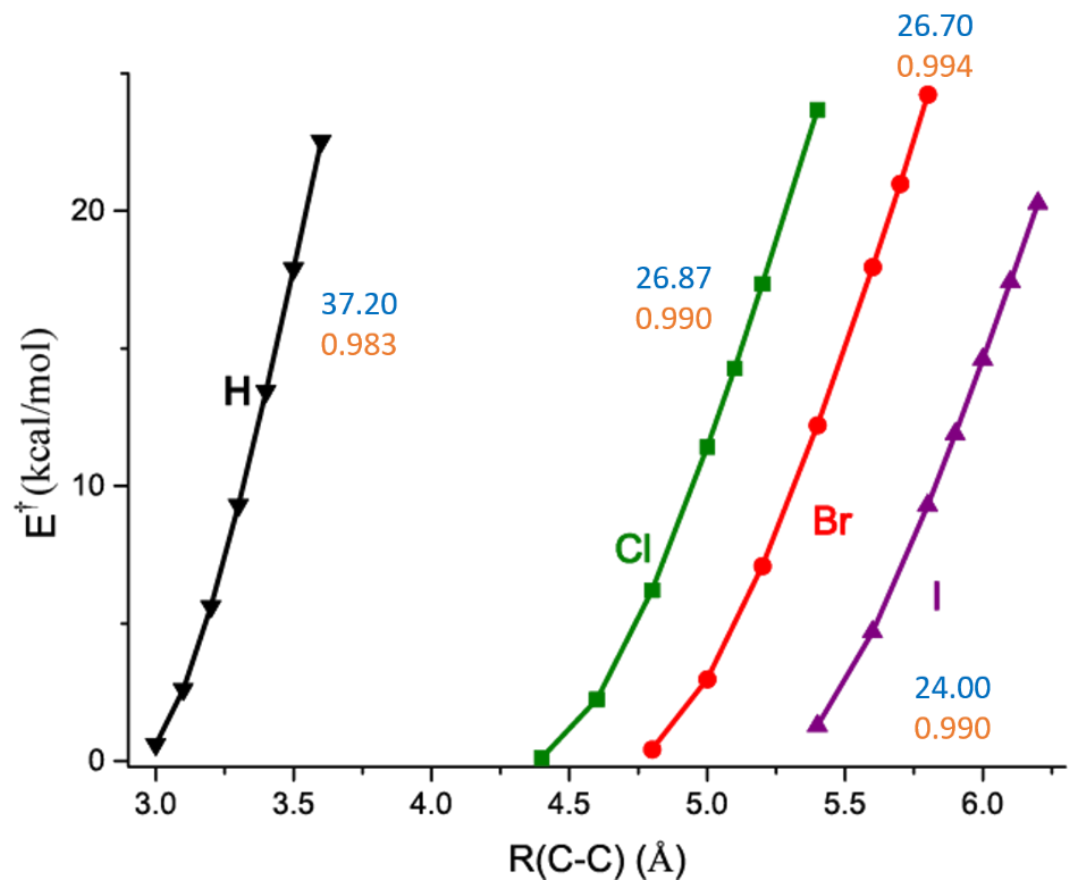

Fig 3. Energy barrier $\mathrm{E}^{\dagger}$ for proton and halogen transfer in symmetric singlet system $\left(\mathrm{H}_{3} \mathrm{C}-\mathrm{X}-\mathrm{CH}_{3}\right)^{+}(\mathrm{X}=$ $\mathrm{H}, \mathrm{Cl}, \mathrm{Br}$ or I). Slopes of fit to linear relationship are shown as blue numbers (kcal/mol- $\AA$ ) and the corresponding correlation coefficients are in orange.

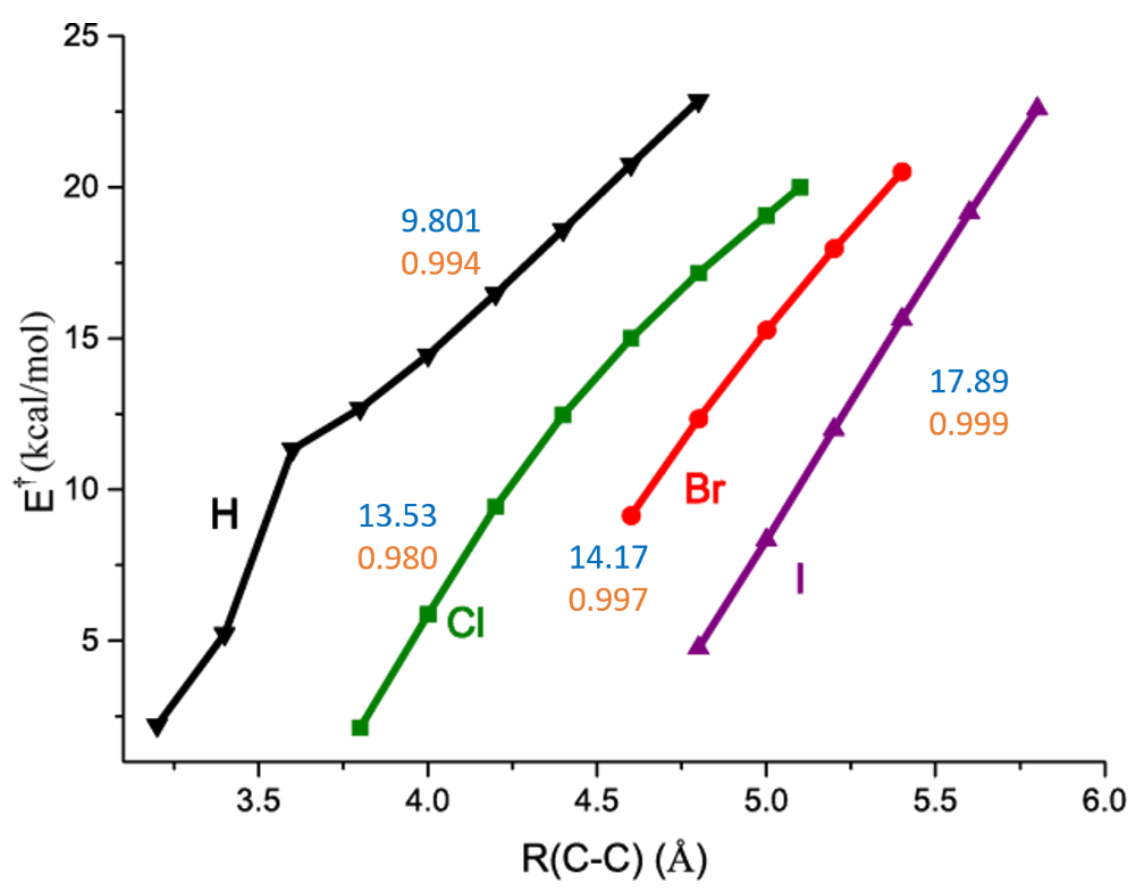

Fig 4. Energy barrier $\mathrm{E}^{\dagger}$ for proton and halogen transfer in triplet $\left(\mathrm{H}_{3} \mathrm{C}-\mathrm{X}-\mathrm{CH}_{3}\right)^{+}(\mathrm{X}=\mathrm{H}, \mathrm{Cl}, \mathrm{Br}$ or $\mathrm{I})$. Slopes of fit to linear relationship are shown as blue numbers (kcal/mol- $\AA$ ) and the corresponding correlation coefficients are in orange. 


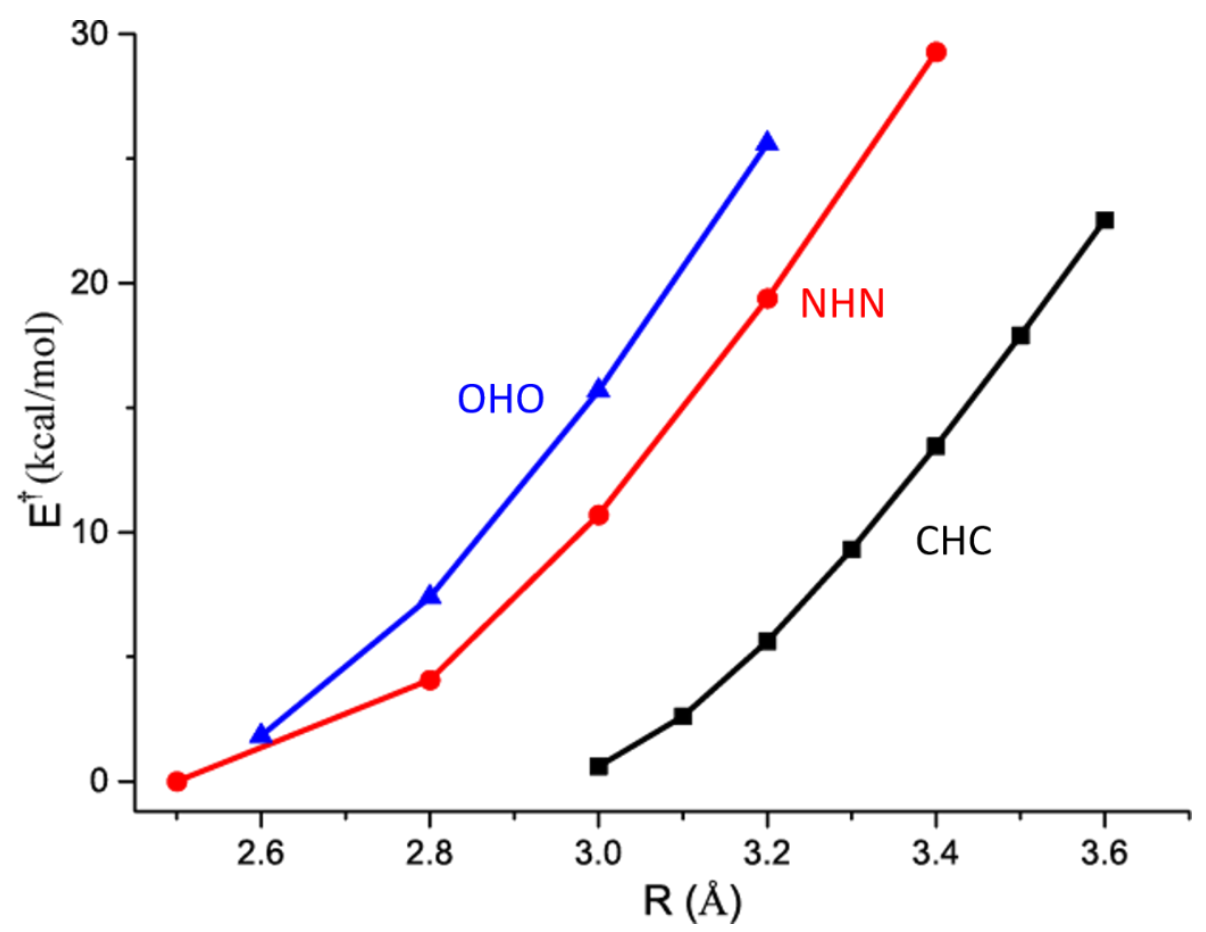

Fig 5. Proton transfer barrier $\mathrm{E}^{\dagger}$ in $\left(\mathrm{H}_{\mathrm{n}} \mathrm{A}-\mathrm{H}-\mathrm{AH}_{\mathrm{n}}\right)^{+}$, all singlet states.

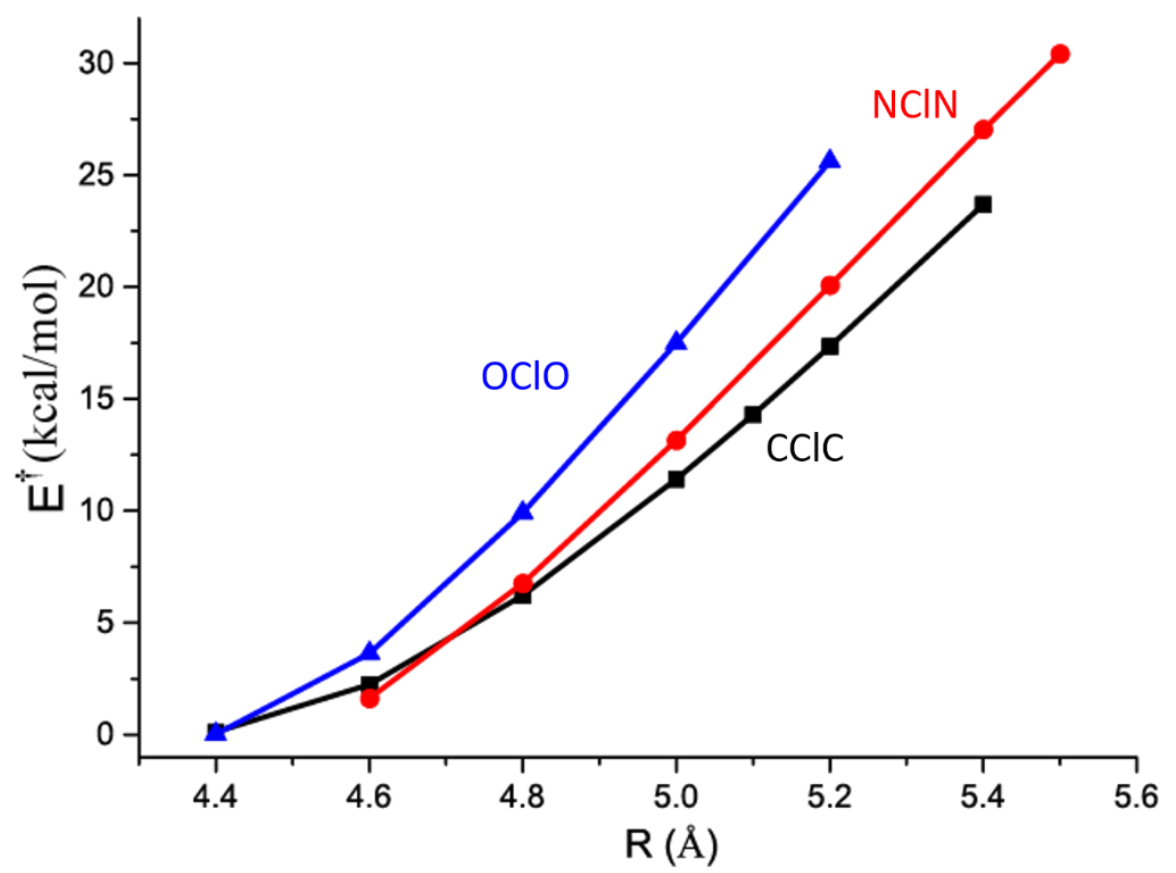

Fig 6. $\mathrm{Cl}$ transfer barrier $\mathrm{E}^{\dagger}$ in $\left[\mathrm{H}_{\mathrm{n}} \mathrm{A}-\mathrm{Cl}-\mathrm{AH}_{\mathrm{n}}\right]^{+}$, all singlet states. 


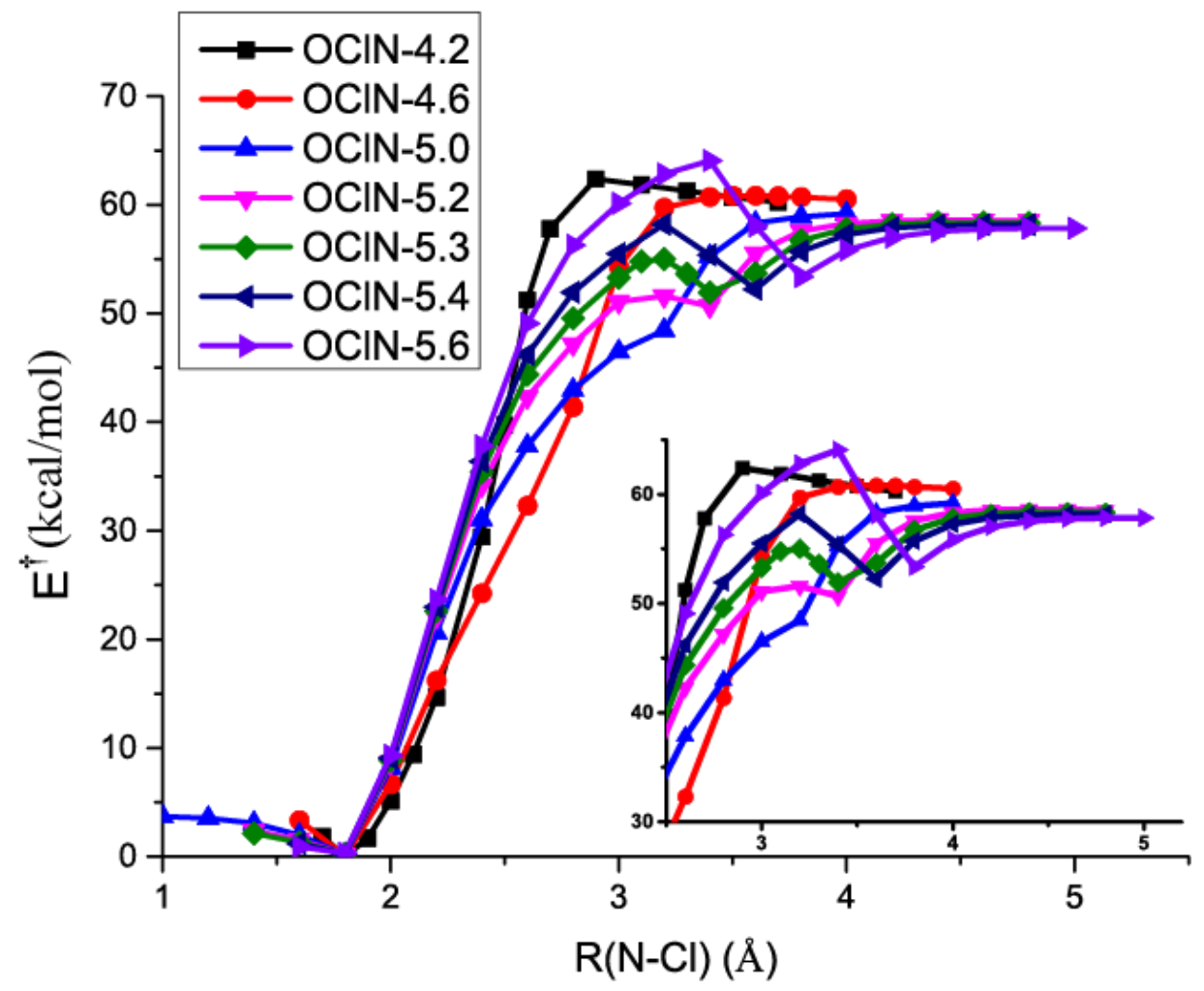

Fig 7. Energy barriers for $\mathrm{Cl}$ transfer from $\mathrm{N}$ to $\mathrm{O}$ in asymmetric system $\left(\mathrm{H}_{3} \mathrm{~N}-\mathrm{Cl}-\mathrm{OH}_{2}\right)^{+}$. 